\title{
Distinct roles for the small GTPases Cdc42 and $R$ ho in endothelial responses to shear stress
}

\author{
Song Li, ${ }^{1}$ Benjamin P.C. Chen, ${ }^{1}$ Nobuyoshi Azuma, ${ }^{2}$ Ying-Li Hu, ${ }^{1}$ Steven Z. Wu, ${ }^{1}$ \\ Bauer E. Sumpio, ${ }^{2}$ John Y.-J. Shyy, ${ }^{1}$ and Shu Chien ${ }^{1}$ \\ ${ }^{1}$ Department of Bioengineering and Institute for Biomedical Engineering, University of California-San Diego, \\ La Jolla, California 92093-0412, USA \\ ${ }^{2}$ Department of Surgery, Yale University School of Medicine, New Haven, Connecticut 06510, USA
}

Address correspondence to: John Y.-J. Shyy, Department of Bioengineering, University of California-San Diego, La Jolla, California 92093-0412, USA. Phone: (619) 822-0785; Fax: (619) 534-3658; E-mail: Shyy@bioeng.ucsd.edu

Received for publication September 29, 1998, and accepted in revised form March 10, 1999.

\begin{abstract}
Shear stress, the tangential component of hemodynamic forces, plays an important role in endothelial remodeling. In this study, we investigated the role of Rho family GTPases Cdc42 and Rho in shear stress-induced signal transduction and cytoskeleton reorganization. Our results showed that shear stress induced the translocation of $\mathrm{Cdc} 42$ and Rho from cytosol to membrane. Although both $\mathrm{Cdc} 42$ and Rho were involved in the shear stress-induced transcription factor AP- 1 acting on the $12-\mathrm{O}$-tetradecanoyl-13-phorbol-acetate-responsive element (TRE), only Cdc42 was sufficient to activate AP-1/TRE. Dominant-negative mutants of $\mathrm{Cdc} 42$ and $\mathrm{Rho}$, as well as recombinant $\mathrm{C} 3$ exoenzyme, attenuated the shear stress activation of c-Jun $\mathrm{NH}_{2}$-terminal kinases (JNKs), suggesting that Cdc42 and Rho regulate the shear stress induction of AP-1/TRE activity through JNKs. Shear stress-induced cell alignment and stress fiber formation were inhibited by the dominant-negative mutants of Rho and $\mathrm{p} 160 \mathrm{ROCK}$, but not by the dominant-negative mutant of $\mathrm{Cdc} 42$, indicating that the Rho-p160ROCK pathway regulates the cytoskeletal reorganization in response to shear stress.
\end{abstract}

J. Clin. Invest. 103:1141-1150 (1999).

\section{Introduction}

Endothelial cells (ECs) in blood vessels are exposed to fluid shear stress, the tangential component of the hemodynamic forces acting on the vessel wall. Shear stress has been implicated in pathophysiological processes in the vascular wall such as atherosclerosis, reperfusion, and EC wound healing (1-8). The role of shear stress in atherogenesis is manifested by the finding that the atherosclerotic lesions in the arterial tree are preferentially located in the disturbed flow region. In vitro experiments using ECs cultured in flow channels have shown that the structure and function of ECs are modulated by shear stress (reviewed in ref. 9). The early responses of ECs to applied shear stress in vitro may represent in vivo responses of ECs to the temporal and spatial changes of shear stress resulting from disturbed flow. It has been shown that shear stress modulates the expression of genes encoding growth factors, adhesion molecules, coagulation molecules, chemoattractants, proto-oncogenes, and vasoactive substances (reviewed in ref. 10). For example, the platelet-derived growth factors, intercellular adhesion molecule-1, monocyte chemotactic protein-1 (MCP-1), and c-fos genes are all transiently upregulated by shear stress (11-14). Several laboratories, including ours, have attempted to define the upstream signaling pathways leading to the expression of these shear-inducible genes. It has been shown that shear stress induces a rapid and transient activation of Ras small GTPase, which in turn regulates the mitogen-activated protein kinases (MAPKs), including extracellular signal-regulated kinases (ERKs) and c-Jun $\mathrm{NH}_{2}$-terminal kinases (JNKs) $(15,16)$. In the downstream, target genes such as the MCP-1 gene are transiently upregulated through the transcription factor activating protein-1 (AP-1) acting on the 12-O-tetradecanoyl-13-phorbolacetate-responsive element (TRE) (17). Long-term exposure of ECs to shear stress causes the elongation of ECs along the direction of flow, with rearranged microfilaments and focal adhesion sites, attenuated cortical Factin, and enhanced central stress fibers (18-21). These structural features are similar to those seen in vivo in ECs in the straight part of the arterial tree (22), an area that is relatively resistant to atherosclerosis. Recent studies indicate that the shear stress modulation of endothelial shape and F-actin network depends on tyrosine kinase activities, intracellular calcium, and an intact microtubule network but that it is independent of protein kinase $\mathrm{C}$, intermediate filaments, and shear- and stretch-activated mechanosensitive channels (23).

Ras-related Rho family GTPases (e.g., Cdc42, Rac, and Rho) have distinct functions in regulating the actinbased cytoskeletal structure (reviewed in refs. 24 and 25): Cdc42 regulates filopodia formation $(26,27)$; Rac regulates membrane ruffling (28); and Rho increases cell contractility, focal adhesions, and actin stress fibers (29). It was also shown that Rho stimulated the tyrosine phosphorylation of focal adhesion kinase (FAK) to augment the onset of stress fiber formation (30-32). Recently, p160ROCK, a Rho-associated serine/threonine kinase that belongs to the Rho-kinase family, has been characterized (33). p160ROCK can enhance myosin light chain (MLC) phosphorylation by inactivating myosin phos- 
phatase and/or directly phosphorylating MLC at the same site as MLC kinase (MLCK) (34-36). The enhanced MLC phosphorylation in turn increases the contractility of actinomyosin, the formation of stress fibers, and the recruitment of integrins to focal adhesions (37). In addition to modulating cell morphology, Rho family GTPases also regulate MAPKs and other kinases (reviewed in ref. 25). Cdc42 and Rac can regulate the JNK pathway $(38,39)$, and Rho is involved in the integrindependent activation of ERK upon cell adhesion (40).

The pivotal roles of Rho small GTPases in regulating the actin-based cytoskeletal structure and MAPK pathways prompted us to investigate their involvement in the EC responses to shear stress. In this study, by using their constitutively active or dominant-negative mutants, we found that $\mathrm{Cdc} 42$ and Rho play distinct roles in shear stress-induced signal transduction and cytoskeleton reorganization.

\section{Methods}

Cell culture. Cell culture reagents were obtained from GIBCO BRL (Grand Island, New York, USA). Bovine aortic endothelial cells (BAECs) were isolated from the bovine aorta either with collagenase or by gently scraping with a rubber policeman. BAECs were cultured in DMEM supplemented with $10 \%$ FCS, $2 \mathrm{mM}$ L-glutamine, and $1 \mathrm{mM}$ each of penicillin-streptomycin and sodium pyruvate. Cell cultures were maintained in a humidified $95 \%$ air $/ 5 \% \mathrm{CO}_{2}$ incubator at $37^{\circ} \mathrm{C}$. All experiments were conducted with cultures prior to passage 10 .

Shear stress experiments. A flow system was used to impose shear stress on cultured ECs as described by Frangos et al. (41). In brief, a glass slide $75 \times 38 \mathrm{~mm}$ seeded with a confluent monolayer of BAECs was mounted in the flow channel created by sandwiching a silicone gasket between the glass slide and an acrylic plate with an inlet and outlet for exposing the cultured cells to the shear stress resulting from flow. The channel is $0.025 \mathrm{~cm}$ in height, $2.5 \mathrm{~cm}$ in width, and $5.0 \mathrm{~cm}$ in length. A laminar shear stress of $12 \mathrm{dyn} / \mathrm{cm}^{2}$ was generated by the flow resulting from a hydrostatic pressure difference between a high and a low reservoir. The flow system was kept at $37^{\circ} \mathrm{C}$ and ventilated with $95 \%$ humidified air $/ 5 \% \mathrm{CO}_{2}$.

\section{Figure 1}

Shear stress induces the translocation of $\mathrm{Cdc} 42$ and Rho. Confluent BAECs were either subjected to a shear stress of $12 \mathrm{dyn} / \mathrm{cm}^{2}$ for various lengths of time as indicated or kept as static controls (represented by time 0 ). The cell lysates were fractionated into cytosol and membrane fractions. Different fractions were separated by $12.5 \%$ SDS-polyacrylamide gel followed by immunoblotting with either a polyclonal anti-Cdc42 or a polyclonal anti-RhoA antibody. Bar graphs represent mean \pm SD from three separate experiments. The relative protein amount is defined as the band intensity of the sheared samples (hatched bars) relative to that of the static control (open bars). Asterisks indicate significant difference $(P<0.05)$ between sheared and static control cells. The bottom of each panel shows G6PDH immunoblotting of the blots from the same lysates indicating that shear stress did not cause the translocation of G6PDH.
Cdc42 and Rho translocation assay and immunoblotting. For Cdc42 and Rho translocation assay, static or sheared BAECs were scraped into a lysis buffer containing $50 \mathrm{mM}$ HEPES ( $\mathrm{pH}$ 7.4), $50 \mathrm{mM} \mathrm{NaCl}, 1 \mathrm{mM} \mathrm{MgCl}_{2}$, $2 \mathrm{mM}$ EDTA, $1 \mathrm{mM}$ PMSF, 10 $\mu \mathrm{g} / \mathrm{ml}$ leupeptin, $1 \mathrm{mM} \mathrm{Na}_{3} \mathrm{VO}_{4}, 5 \mathrm{mM} \mathrm{NaF}$, and $1 \mathrm{mM}$ DTT. The cell lysates were passed through a 27 -gauge needle five times to disrupt the cell membranes for the release of the cytosol proteins. The lysates were ultracentrifuged at $10^{5} \mathrm{~g}$ for one hour. After collecting the supernatant as the cytosol fraction, the pellet was resuspended in $1 \%$ Triton X-100 in the lysis buffer and centrifuged at $10,000 \mathrm{~g}$ for $10 \mathrm{~min}$. After this centrifugation, the supernatant was collected as the membrane fraction, and the pellet was dissolved in SDS loading buffer as the Triton X-100 insoluble fraction that included the cytoskeleton and nuclei. The amounts of $\mathrm{Cdc} 42$ and RhoA in each fraction were determined by immunoblotting with polyclonal antiCdc 42 or polyclonal anti-RhoA (Santa Cruz Biotechnology Inc., Santa Cruz, California, USA). The three separated fractions were subjected to $12.5 \%$ SDS-PAGE, and the proteins in the gel were transferred to a nitrocellulose membrane. The membrane was blocked with $3 \%$ nonfat milk, followed by incubation with the primary antibody in TTBS (10 mM Tris- $\mathrm{HCl}$ [pH 7.4], 150 $\mathrm{mM} \mathrm{NaCl}$, and $0.05 \%$ Tween-20) containing $0.1 \%$ BSA. The bound primary antibodies were detected by using a goat antimouse or goat anti-rabbit IgG/horseradish peroxidase conjugate (Santa Cruz Biotechnology Inc.) and viewed by using the a
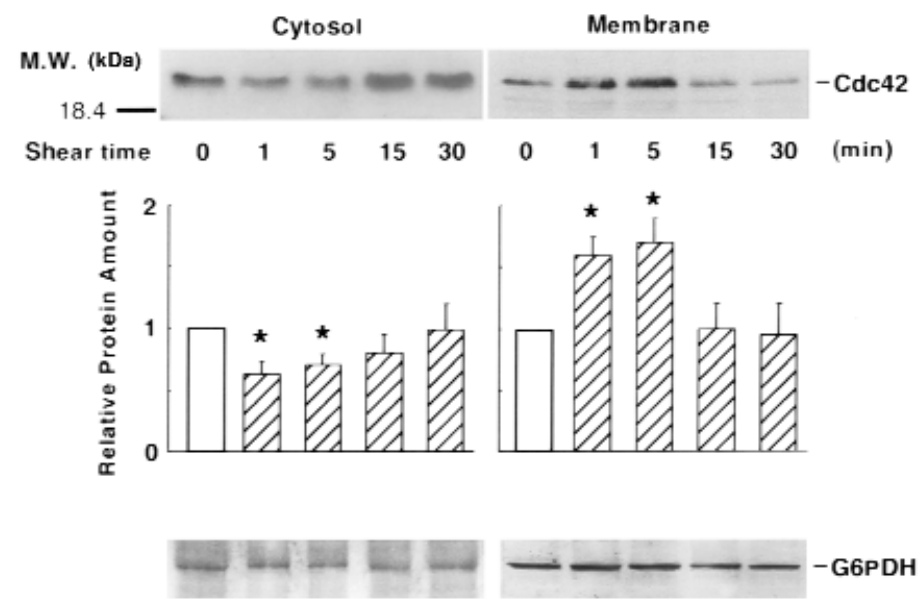

b
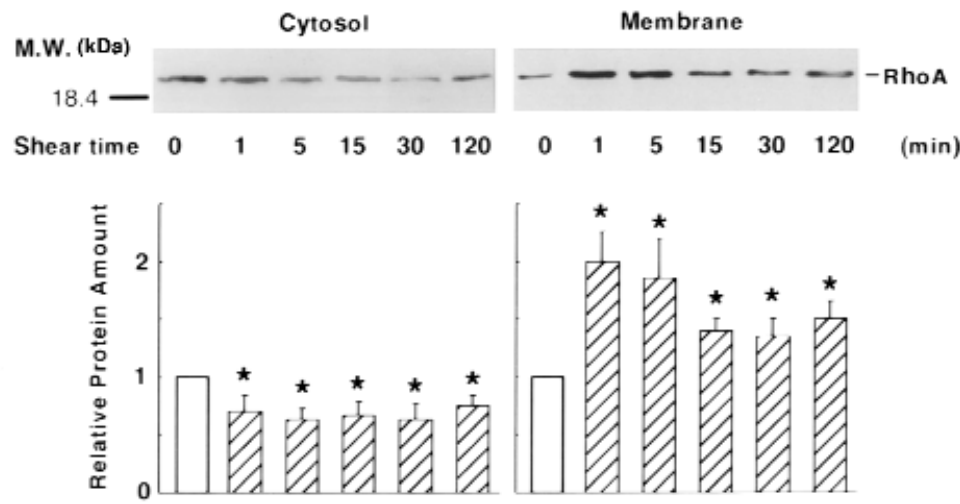
ECL detection system (Amersham Life Sciences Inc., Arlington Heights, Illinois, USA). The same cell lysates were also used for immunoblotting with antibody against glucose-6-phosphate dehydrogenase (G6PDH) (Sigma Chemical Co., St. Louis, Missouri, USA) as internal controls.

Plasmids, transient transfection, and promoter activity assay. Plasmids encoding hemagglutinin (HA)-JNK1, dominant-active mutants myc-Cdc42(V12) and myc-RhoA(V14), and dominantnegative mutants HA-Cdc42(N17) and HA-RhoA(N19) were described previously $(38,40,42,43)$. Plasmids encoding the myc epitope-tagged p160ROCK (myc-ROCK) and the dominantnegative mutant myc-ROCK-C encoding a $\mathrm{COOH}$-terminal fragment of p160ROCK truncated at amino acid 1080 (33) were gifts from Shuh Narumiya (Kyoto University, Kyoto, Japan).

The various plasmids were transfected into BAECs using the lipofectamine method (GIBCO BRL). After incubation for six hours, the cells were washed with fresh DMEM and cultured with DMEM supplemented with $10 \%$ FCS to reach confluence. Within $48 \mathrm{~h}$ after transfection, the BAEC monolayers were subjected to shear stress experiments or kept as static controls. The expression of the various exogenous genes was monitored by immunoblotting with anti-HA mAb 12CA5 (Boehringer Mannheim Biochemicals, Indianapolis, Indiana, USA), anti-myc $\mathrm{mAb}$ (Santa Cruz Biotechnology Inc.), anti-Cdc42, or anti-Rho.

For TRE promoter activity assay, expression plasmids encoding the wild-types or mutants of the small GTPases were cotransfected with 4XTRE-Pl-Luc into BAECs as described previously (29). Plasmid pSV- $\beta$-galactosidase ( $\beta$-gal), which contains a $\beta$-gal gene driven by the SV40 promoter and an enhancer, was cotransfected to monitor the transfection efficiency. After experiments, the cells were lysed with a lysis buffer containing $0.1 \mathrm{M}$ potassium phosphate ( $\mathrm{pH} 7.9$ ), $0.5 \%$ Triton X-100, and $1 \mathrm{mM} \mathrm{DTT}$ to release the luciferase and $\beta$-gal. Luciferase assays were carried out by adding a buffer containing $2 \mathrm{mM} \mathrm{ATP}$, and $0.075 \mathrm{mM}$ luciferin, 100 $\mathrm{mM}$ tricine, $10 \mathrm{mM} \mathrm{Mg}_{2} \mathrm{SO}_{4}$, and $2 \mathrm{mM}$ EDTA ( $\mathrm{pH}$ 7.8) to the lysate and measuring the total light output in a luminometer. For $\beta$-gal activity assays, $1 \mathrm{mg} / \mathrm{ml}$ o-nitrophenyl-

\section{Figure 2}

Cdc42 and Rho regulate the shear stress activation of AP-1/TRE transcriptional activity. (a) BAECs cultured on glass slides were transfected with pcDNA3, HA-Cdc42(N17), or HA-RhoA(N19) (2 $\mu \mathrm{g} / \mathrm{slide})$, together with 4 XTRE-PI-Luc $(1 \mu \mathrm{g} / \mathrm{slide})$ and $\beta$-gal $(0.5$ $\mu \mathrm{g} /$ slide). Approximately $40 \mathrm{~h}$ after transfection, the confluent BAEC monolayers were either sheared at $12 \mathrm{dyn} / \mathrm{cm}^{2}$ for eight hours or kept under static conditions for eight hours, followed by luciferase and $\beta$-gal assays. The luminometer readings for luciferase were normalized by $\beta$-gal activities. (b) 4XTRE-PI-Luc ( $1 \mu \mathrm{g} / \mathrm{slide})$ and $\beta$-gal $(0.5 \mu \mathrm{g} / \mathrm{slide})$ were cotransfected with pcDNA3, mycCdc42(V12), myc-RhoA(V14), myc-Cdc42(V12) together with HARhoA(N19), or myc-RhoA(V14) together with HA-Cdc42(N17) (2 $\mu \mathrm{g} /$ slide for each plasmids). The total amount of the transfected plasmid DNA in the various samples was kept constant by supplementing with pcDNA3. About $40 \mathrm{~h}$ after transfection, the cells were lysed for luciferase and $\beta$-gal activities assays. Bar graphs, representing mean \pm SD from three separate experiments, show the normalized luciferase activity of the various samples relative to that in the pcDNA3-transfected, static controls. Asterisks in a indicate significant difference $(P<0.05)$ compared with pcDNA3-transfected cells after shearing. Asterisks in $\mathbf{b}$ indicate significant difference $(P$ $<0.05$ ) compared with pcDNA3-transfected cells. The bottom of a shows immunoblotting with anti-HA mAb; the bottom of $\mathbf{b}$ shows immunoblotting with polyclonal anti-Cdc42, polyclonal anti-RhoA, or anti-HA mAb indicating that the levels of the expressed exogenous proteins were comparable among the various samples.
D-galactopyranoside in $0.1 \mathrm{M}$ dibasic sodium phosphate, 1.2 $\mathrm{mM} \mathrm{MgCl}$, and $60 \mathrm{mM} \beta$-mercaptoethanol was added to the lysate. The mixture was incubated for $30 \mathrm{~min}$ at $37^{\circ} \mathrm{C}$, and the absorbance at $410 \mathrm{~nm}$ was determined by a spectrophotometer. The results of the luciferase assays were normalized to the readings of the $\beta$-gal assays.

Immunoprecipitation and kinase activity assay. For HA-JNK1 kinase assay, plasmids encoding the epitope-tagged HA-JNK1 (1 $\mu \mathrm{g} /$ slide) were cotransfected with plasmids encoding the various constitutively active or dominant-negative mutants $(2 \mu \mathrm{g} /$ slide $)$ into BAECs. After $48 \mathrm{~h}$, BAECs were either kept as static controls or sheared for $30 \mathrm{~min}$, and lysed in a kinase lysis buffer containing $25 \mathrm{mM}$ HEPES [pH 7.4], $0.5 \mathrm{M} \mathrm{NaCl}, 1 \%$ Triton X-100, $0.1 \%$ SDS, $1 \%$ deoxycholate, $5 \mathrm{mM}$ EDTA, $1 \mathrm{mM}$ PMSF, 10 $\mu \mathrm{g} / \mathrm{ml}$ leupeptin, $50 \mathrm{mM} \mathrm{NaF}, 10 \mathrm{mM} \mathrm{Na}_{3} \mathrm{VO}_{4}$, and $2 \mathrm{mM} \beta$ glycerophosphate. The lysates were centrifuged at $12,000 \mathrm{~g}$ for $15 \mathrm{~min}$., and the supernatants were immunoprecipitated with anti-HA mAb 12CA5 and protein A-Sepharose beads (Pharmacia Biotech, Ameda, California, USA) at $4^{\circ} \mathrm{C}$ overnight. Two micrograms of glutathione S-transferase (GST)-c-Jun(1-79) fusion protein and $10 \mu \mathrm{Ci}\left[\gamma^{32} \mathrm{P}\right] \mathrm{ATP}$ in $30 \mu \mathrm{l}$ of a kinase assay buffer containing $25 \mu \mathrm{M}$ ATP were added to each immunocomplex pellet to carry out the kinase reaction at $30^{\circ} \mathrm{C}$ for 20 $\mathrm{min}$. The reaction was stopped by adding $4 \times$ SDS sample buffer containing $250 \mathrm{mM}$ Tris- $\mathrm{HCl}$ ( $\mathrm{pH} 6.8$ ), 8\% SDS, 40\% glycerol, $20 \% \beta$-mercaptoethanol, and $0.02 \%$ bromophenol blue. The phosphoproteins were separated by SDS-PAGE for autoradiography. The intensities of phosphorylated bands were quantified

a
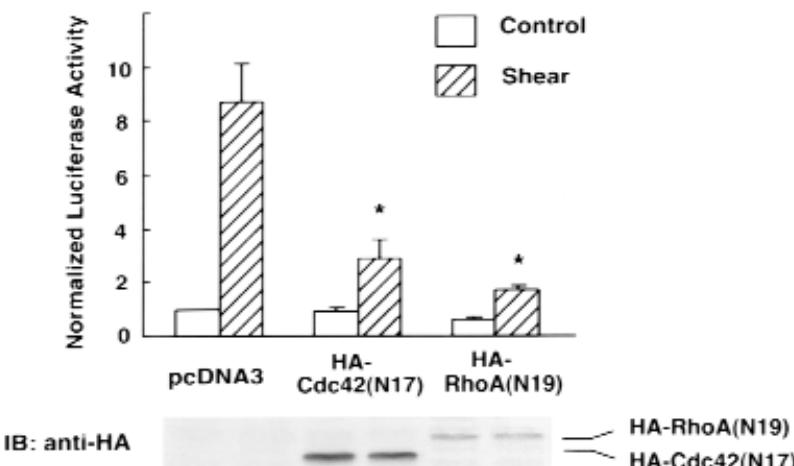

b
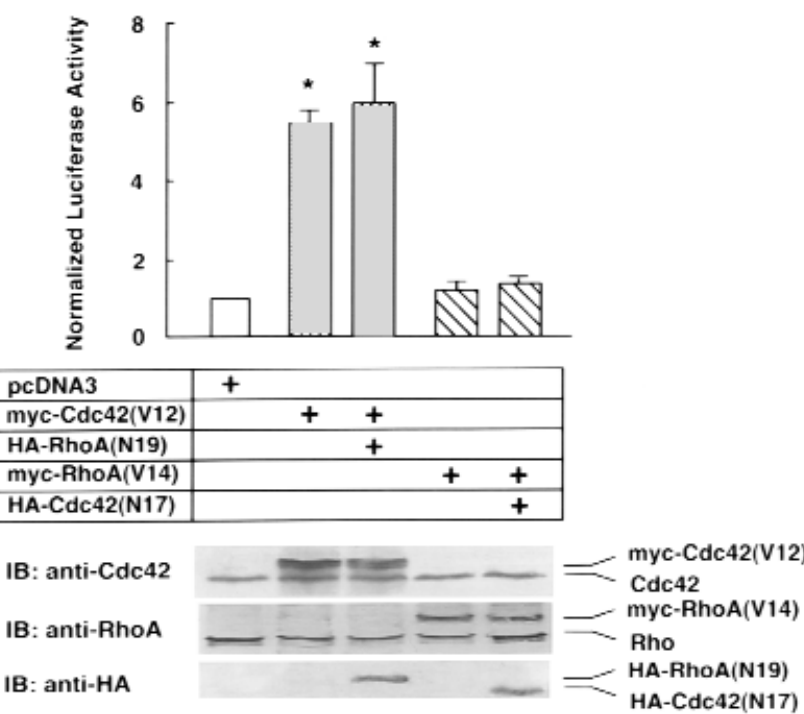


\section{Figure 3}

Cdc42 and RhoA regulate the shear stress activation of JNK. (a) HAJNK1 (1 $\mu \mathrm{g} /$ slide) was cotransfected with pcDNA3, HACdc42(N17), or HA-RhoA(N19) (2 $\mu \mathrm{g} /$ slide) into BAECs cultured on glass slides. The total amount of the transfected plasmid DNA in the various samples was kept constant by supplementing with pcDNA3. About $40 \mathrm{~h}$ after transfection, the confluent BAEC monolayers were either sheared at $12 \mathrm{dyn} / \mathrm{cm}^{2}$ for $30 \mathrm{~min}$ or kept under static conditions for $30 \mathrm{~min}$. The cell lysates were immunoprecipitated with a polyclonal anti-JNK1 antibody, and GST-c-Jun(1-79) and $(\gamma-32$ P)ATP were added to the immunoprecipitates for immunocomplex kinase assays. The bands indicated by the arrow represent the phosphorylated GST-c-Jun(1-79). Shown at bottom is the immunoblotting with anti-HA mAb indicating that the levels of $\mathrm{HA}$ JNK1 were comparable among the various samples. The expression levels of transfected HA-Cdc42(N17) and HA-RhoA(N19) were also shown in the immunoblot. (b) Confluent monolayers of BAECs were treated with or without $6.5 \mu \mathrm{g} / \mathrm{ml}$ recombinant $\mathrm{C} 3$ for $48 \mathrm{~h}$. The cells were then either sheared at $12 \mathrm{dyn} / \mathrm{cm}^{2}$ for 30 min or kept under static conditions, followed by JNK1 kinase activity assays. The bar graphs, representing mean \pm SD from three separate experiments, show the JNK kinase activity of the various samples relative to that in the pcDNA-transfected cells and static controls in $\mathbf{a}$, and relative to that in the static control without $\mathrm{C} 3$ pretreatment in $\mathbf{b}$. Asterisks in a indicate significant difference $(P<0.05)$ compared with pcDNA3transfected cells after shearing. Asterisks in $\mathbf{b}$ indicate significant difference $(P<0.05)$ compared with control cells after shearing.

by densitometric analysis. Similar procedures were used for the endogenous JNK1 kinase assay, except that polyclonal anti-JNK1 was used for immunoprecipitation.

Immunostaining, confocal microscopy, and cell morphology analysis. To test whether Cdc42, Rho, and p160ROCK regulate shear stress-induced cell alignment and stress fiber formation, plasmids encoding the HA-Cdc42(N17), HARhoA(N19), myc-ROCK-WT, or myc-ROCK-C ( $2 \mu \mathrm{g}$ /slide $)$ were transfected into BAECs. As transfection controls, plasmids encoding pcDNA3 $(1 \mu \mathrm{g} /$ slide $)$ and $\beta$-gal $(1 \mu \mathrm{g} /$ slide $)$ were cotransfected into BAECs. After $48 \mathrm{~h}$, the transfected cells were either sheared for $16 \mathrm{~h}$ or kept as static controls. The cells were then fixed in 4\% paraformaldehyde in PBS for 10 min, followed by permeabilization with $0.5 \%$ Triton X-100 in PBS for $10 \mathrm{~min}$. The specimens were incubated in PBS containing mouse anti- $\beta$-gal $\mathrm{mAb}(1: 1,000$; Sigma Chemical Co.), antiHA mAb $(1: 1,000)$, or anti-myc $\mathrm{mAb}(1: 1,000)$ at room temperature for one hour. After washing three times with PBS, the specimens were incubated with rhodamine-conjugated goat anti-mouse IgG and FITC-conjugated phalloidin (5 U/ml; Molecular Probes Inc., Eugene, Oregon, USA) for one hour. Double staining of actin and HA, myc, or $\beta$-gal was observed under a confocal microscopy system (MRC-1000; Bio-Rad Laboratories Inc., Hercules, California, USA) equipped with an argon/krypton laser line, a scan head, and a Nikon Diaphot 300 inverted microscope (Nikon Inc., Melville, New York, USA). FITC was excited at a wavelength of $488 \mathrm{~nm}$ and detected within a band between 506 and $538 \mathrm{~nm}$. Rhodamine was excited at $568 \mathrm{~nm}$ and detected within a band between 589 and $621 \mathrm{~nm}$.

To quantify cell morphological changes, an imaging system including a Nikon Diaphot 300 microscope, a charge-coupled device-camera (Optronics Engineering, Gòleta, California, USA), and a computer was used. A large number of transfected cells were randomly selected. The rhodamine-staining and phase-contrast images were collected by using IMAGE I software (Universal Imaging, West Chester, Pennsylvania, USA). The boundary of transfected cells was outlined by IMAGE I automatically, or by hand drawing when necessary. Cell area, a
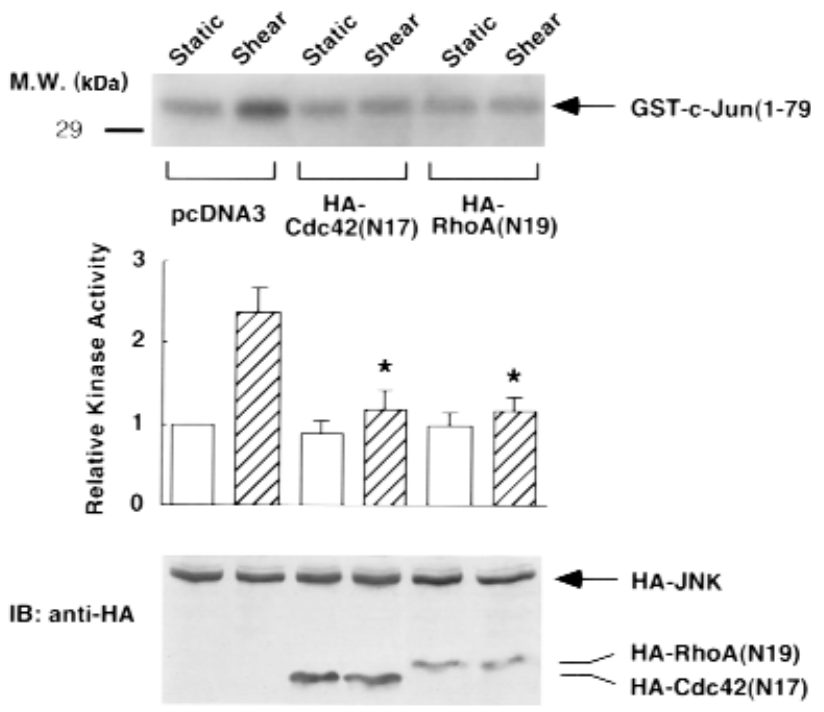

b

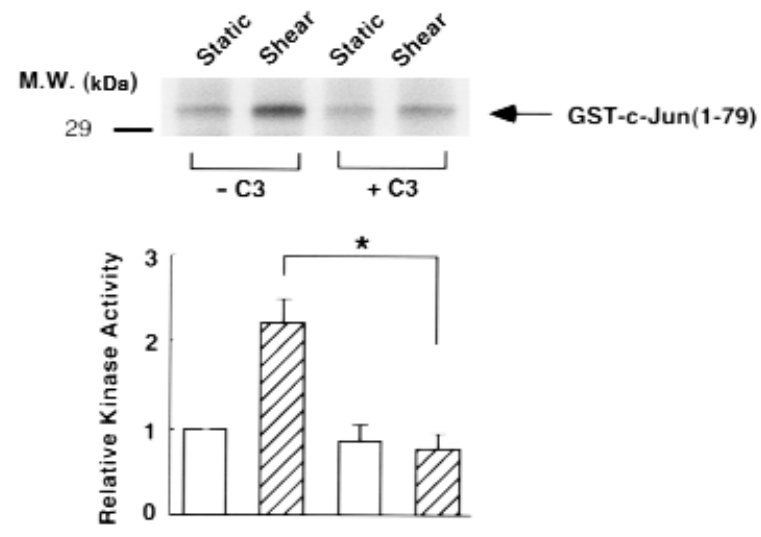

cell perimeter, and the orientation angle between the cell principal axis and the flow direction were automatically measured by IMAGE I. The cell morphology was represented by the orientation angle between the cell principal axis and the flow direction and by the cell shape index, defined as $(4 \pi \times$ cell area)/(cell perimeter squared). The value of the shape index is 1 for a perfectly round cell and decreases toward 0 as the cell approaches a line.

\section{Results}

Shear stress induces the translocation of Cdc42 and Rho in ECs. Several types of chemical stimuli cause the translocation of Rho GTPases from cytosol to membrane or cytoskeleton upon activation $(25,44-46)$. We first investigated whether shear stress, like those chemical stimuli, causes the translocation of these small GTPases in ECs. Cell lysates from static or sheared cells were separated into cytosol, membrane, and cytoskeleton fractions. The amounts of Cdc42 and Rho in these samples were determined by immunoblotting with polyclonal antibodies against Cdc42 or RhoA. As shown in immunoblots in Figure 1a, the application of a flow with a shear stress of $12 \mathrm{dyn} / \mathrm{cm}^{2}$ caused a transient increase in Cdc42 association with the membrane, whereas the amount in the 
cytosol decreased. The translocation occurred as early as one minute and peaked at five minutes. At 15 min after shearing, the distribution of $\mathrm{Cdc} 42$ returned to that in the static control. Figure $1 \mathrm{~b}$ shows that RhoA also translocated to the cell membrane in response to shear stress and that this translocation was sustained for at least two hours, which differed from the transient translocation of Cdc42. The same lysates were used for immunoblotting with a polyclonal anti-G6PDH, which revealed that the levels of this housekeeping protein in both the cytosol and membrane fractions were not affected by the applied shear stress. In contrast to the translocation between the cytosol and membrane fractions, there was little change in the amounts of Cdc42 and Rho in the cytoskeletal fraction (data not shown).

$C d c 42$ and Rho regulate the shear stress activation of AP$1 /$ TRE. We have previously shown that shear stress induces a transient activation of Ras and JNK, which in turn regulate the AP-1/TRE-mediated transcriptional activation in ECs (16). To test whether Cdc42 and Rho are involved in the shear stress activation of AP-1/TRE, BAECs were transfected with 4XTRE-Pl-Luc together with pcDNA3 empty vector, or HA-Cdc42(N17) or HARhoA(N19), the respective dominant-negative mutants of Cdc42 and RhoA. As shown in Figure 2a, in cells transfected with the empty vector pcDNA3, shear stress caused a ninefold increase in TRE luciferase activity when compared with static controls. This shear stress-induced luciferase activity was markedly attenuated in cells cotransfected with HA-Cdc42(N17) or HA-RhoA(N19), with $65 \%$ and $80 \%$ of inhibition, respectively. These results suggest that $\mathrm{Cdc} 42$ and RhoA play significant roles in the shear stress activation of AP- $1 /$ TRE.

To test whether activation of Cdc42 or RhoA alone is sufficient to augment the AP-1/TRE-mediated transcriptional activation, 4XTRE-Pl-Luc was cotransfected with myc-Cdc42(V12) or myc-RhoA(V14), the respective activated mutants of Cdc 42 and RhoA. As shown in Figure $2 \mathrm{~b}$, overexpression of myc-Cdc42(V12) in BAECs caused an increase in luciferase activity by more than fivefold compared with the control cells cotransfected with pcDNA3 empty vector. In contrast, mycRhoA(V14) had little effect on the induction of 4XTREPl-Luc. These results, in conjunction with those in Figure $2 \mathrm{a}$, suggest that both $\mathrm{Cdc} 42$ and RhoA activation are involved but that only $\mathrm{Cdc} 42$ activation is sufficient for the shear stress induction of AP-1/TRE. To investigate the relation between $\mathrm{Cdc} 42$ and Rho in the activation of AP-1/TRE, myc-Cdc42(V12) and 4XTRE-Pl-Luc were cotransfected with HA-RhoA(N19). Overexpression of HA-RhoA(N19) did not attenuate the mycCdc42(V12)-induced luciferase activity (Figure 2b), indicating that RhoA and $\mathrm{Cdc} 42$ independently regulate the shear stress induction of AP-1/TRE.

$\mathrm{Cdc42}$ and RhoA regulate the shear stress activation of JNK. To test whether Cdc42 and RhoA are involved in the shear stress activation of JNK, BAECs were transfected with the epitope-tagged HA-JNK1 together with HACdc42(N17) or HA-RhoA(N19). The transfected cells were either subjected to shear stress for $30 \mathrm{~min}$ or kept as static controls, followed by immunocomplex kinase activity assays. As shown in Figure 3a, shear stress increased the activity of HA-JNK1 by 2.5 -fold in the pcDNA3-transfected controls. Cotransfection of either HA-Cdc42(N17) or HA-RhoA(N19) attenuated the shear stress activation of HA-JNK1, indicating that the shear stress activation of JNK requires Cdc 42 or RhoA. We also used Clostridium botulinum $\mathrm{C} 3$ exoenzyme (C3), a specific inhibitor of Rho (47), in an attempt to block the shear stress activation of JNK. Pretreating BAECs with C3 for $48 \mathrm{~h}$, an experimental condition to cause the formation of the ADP-ribosylated Rho (48), blocked the shear stress activation of JNK (Figure $3 \mathrm{~b}$ ).

To test whether Cdc42 and RhoA are sufficient to regulate JNK in response to shear stress, HA-JNK1 was cotransfected with myc-Cdc42(V12) or myc-RhoA(V14) to mimic the shear stress-activated $\mathrm{Cdc} 42$ or RhoA. As shown in Figure 4, overexpression of myc-Cdc42(V12) caused a drastic activation of HA-JNK1. However, HAJNK1 was not activated in myc-Rho(V14)-transfected

\begin{abstract}
Figure 4
Cdc42, but not RhoA, is sufficient for JNK activation. HA-JNK1 (1 $\mu \mathrm{g} /$ slide) was cotransfected with pcDNA3, myc-RhoA(V14), myc-Cdc42(V12), $\operatorname{Ras}(\mathrm{V} 12)$, myc-Cdc42(V12) together with Ras(N17), or Ras(V12) together with HA-Cdc42(N17) (2 $\mu \mathrm{g} /$ slide for each). The total amount of the transfected plasmid DNA in the various samples was kept constant by supplementing with pcDNA3. About 40 $\mathrm{h}$ after transfection, the cells were lysed and kinase assay was performed on HA-JNK1. The bar graphs, representing mean \pm SD from three separate experiments, show the JNK kinase activity of the various samples relative to that in the pcDNA3-transfected controls. Asterisks indicate significant difference $(P$ $<0.05)$ compared with pcDNA3-transfected cells. Ras(N17) or HA-Cdc42(N17) have no inhibitory effects on JNK activity induced by myc-Cdc42(V12) or Ras(V12). Shown at bottom is the immunoblotting, indicating that similar levels of HA-JNK1 were expressed in various samples.
\end{abstract}

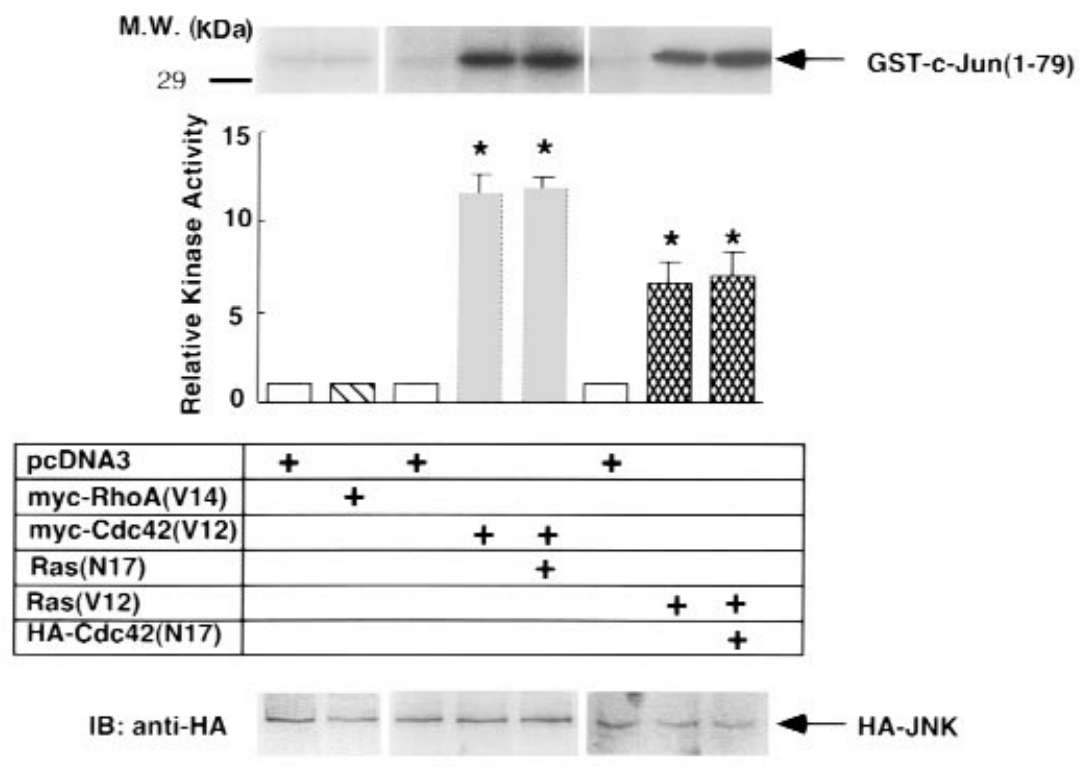

The Journal of Clinical Investigation | April 1999 | Volume 103 | Number 8 

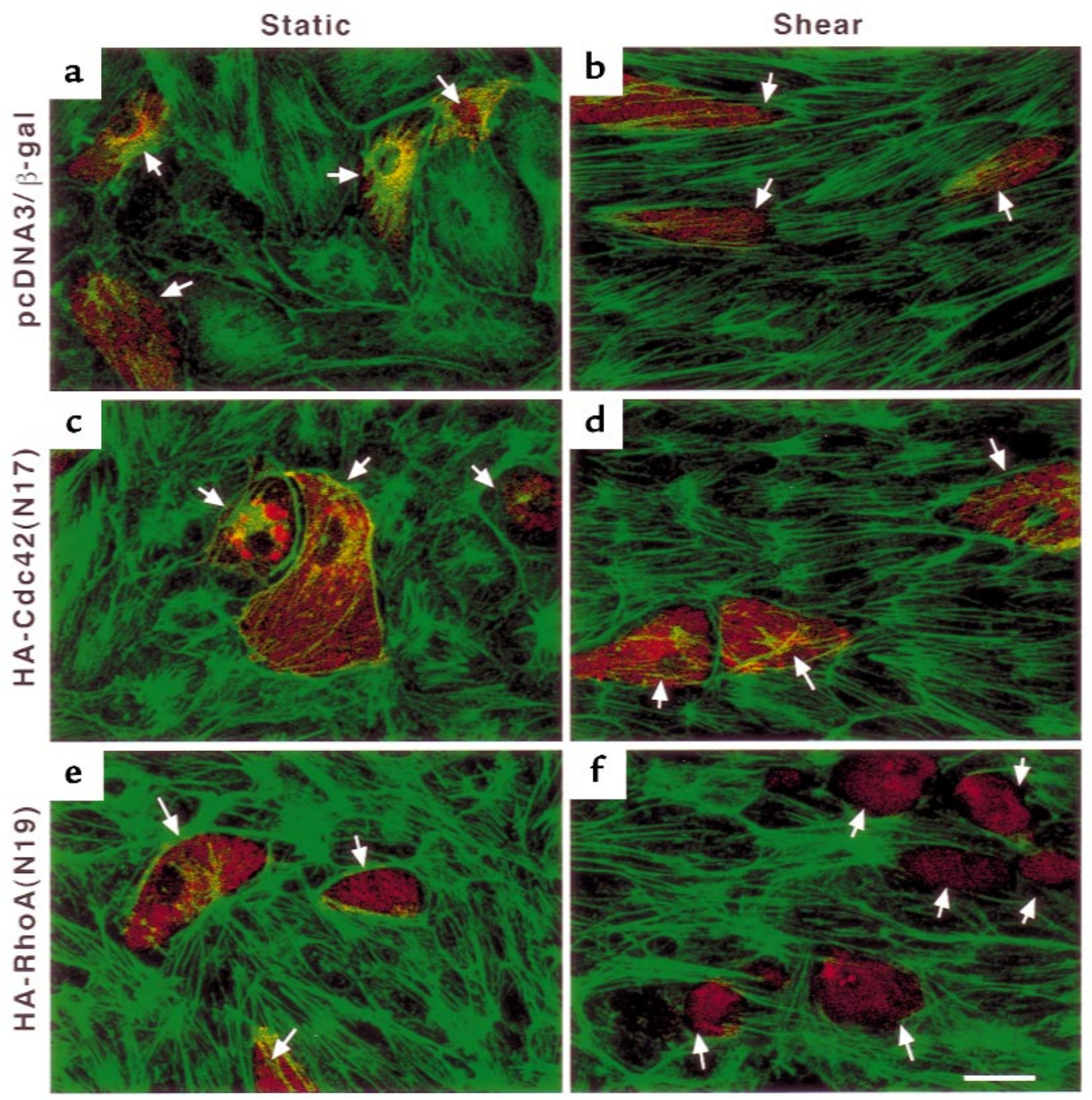

Figure 5

Rho is involved in the shear stress regulation of EC alignment and stress fiber formation. BAECs cultured on glass slides were transfected with pcDNA3 ( $1 \mu \mathrm{g} / \mathrm{slide})$ together with $\beta$-gal (1 $\mu \mathrm{g} / \mathrm{slide})$ (a and b), HA-Cdc42(N17) $(2 \mu \mathrm{g} / \mathrm{slide})(\mathbf{c}$ and d), and HA-RhoA(N19) ( $2 \mu \mathrm{g} /$ slide) (e and f). About $40 \mathrm{~h}$ after transfection, the confluent BAEC monolayers were either sheared at $12 \mathrm{dyn} / \mathrm{cm}^{2}$ for $16 \mathrm{~h}(\mathbf{b}, \mathbf{d}$, and $\mathbf{f})$ or kept under static conditions for $16 \mathrm{~h}(\mathbf{a}$, $\mathbf{c}$, and $\mathbf{e})$. The cells were fixed, permeabilized, double stained for actin and the expressed $\beta$-gal-or HA-tagged proteins, and observed by confocal microscopy. The actin-based cytoskeletal structure, which was recognized by FITC-conjugated phalloidin, is shown in green; the transfected cells, marked by anti- $\beta$-gal mAb or anti-HA mAb recognized by rhodamine-conjugated goat anti-mouse IgG, are shown in red (arrows). Scale bar: $20 \mu \mathrm{m}$.

cells or in pcDNA3-transfected cells. These results, together with those presented in Figure 3, indicate that Cdc42 was involved and sufficient for the shear stress activation of JNK. However, RhoA was involved but was not sufficient for such an activation. Because Ras has been shown to regulate the shear stress activation of JNK $(16,49)$, we tested whether Cdc42 and Ras function sequentially upstream of JNK. Cotransfection of Ras(N17) did not block myc-Cdc42(V12)-induced JNK activity, nor did HA-Cdc42(N17) block Ras(V12)induced JNK activity (Figure 4), suggesting that Cdc42 and Ras activate JNK through independent mechanisms.

Rho is involved in the shear stress regulation of cell alignment and stress fiber formation. Prolonged exposure of ECs to shear stress results in their elongation along the direction of flow (18), the formation of stress fibers, and rearrangement of the microfilaments (20). To test whether Cdc42 or RhoA regulates shear stress-induced cell alignment and stress fiber formation, BAECs were transfected with HA-Cdc42(N17), HA-RhoA(N19), or a combination of pcDNA3 and $\beta$-gal as transfection controls. The cells were either sheared for $16 \mathrm{~h}$ or kept as static controls, followed by double fluorescence staining of actin and the HA epitope tag or $\beta$-gal to indicate the transfected cells. As shown in Figure 5, the pcDNA3-transfected cells aligned with the direction of flow and formed stress fibers after $16 \mathrm{~h}$ of shearing (Figure 5b). Transfection of HACdc42(N17) did not inhibit the shear stress-induced cell alignment and stress fiber formation (Figure $5 \mathrm{~d}$ ). In contrast, transfection of HA-RhoA(N19) caused a decrease of stress fibers under static conditions (Figure 5e) and reduced shear stress-induced stress fiber formation and cell alignment (Figure 5f). The data on the cell orientation angle and cell shape index from the specimens exem- 
plified in Figure 5 were subjected to statistical analysis (Figure 7). Under static conditions, transfection of HACdc42(N17) had no significant effect on cell orientation angle but significantly increased the cell shape index. After $16 \mathrm{~h}$ of shearing, the orientation angle of the cells transfected with HA-Cdc42(N17) was not significantly different from that of cells transfected with pcDNA3, and the shape index of HA-Cdc42(N17)-transfected cells decreased but was still significantly higher than that of transfected pcDNA3 controls after shearing $(P<0.05)$. HA-RhoA(N19) had no effects on cell orientation angle or cell shape index under static conditions, but it significantly reduced the cell alignment and cell shape change caused by shear stress $(P<0.05)$ compared with pcDNA3transfected cells, indicating that Rho regulates stress fiber formation and cell alignment in response to shear stress. p160ROCK is the Rho effector to regulate shear stress-induced cytoskeleton reorganization. The Rho-associated kinase p160ROCK has been shown to function downstream of Rho in regulating the formation of stress fibers and focal adhesions. ROCK-C, a dominant-negative mutant of p160ROCK in which the segment from the $\mathrm{NH}_{2}$-terminus to the Rho-binding domain in the wild-type p160ROCK is truncated, has been shown to inhibit Rho-induced formation of stress fibers and focal adhesions (33). We used epitope-tagged myc-ROCK-C to determine whether p160ROCK plays a role in the shear stress-induced cytoskeleton reorganization. As shown in Figure 6a, transfection of the wild-type myc-ROCK increased stress fibers and did not affect shear stress-induced cell alignment (Figure 6b). In contrast, transfection of myc-ROCK-C decreased stress fiber formation under static conditions (Figure $6 \mathrm{c}$ ) and reduced the shear stress-induced stress fiber formation and cell alignment (Figure 6d). Like HA-RhoA(N19), mycROCK-C had no significant effects on cell orientation angle and shape index under static conditions, but it attenuated the decrease of cell orientation angle and shape index caused by shear stress (Figure 7). After 16 $h$ of shearing, the cell orientation angle and shape index in myc-ROCK-C-transfected cells were significantly higher than those in myc-ROCK-transfected cells $(P<0.05)$.

\section{Discussion}

Rho family GTPases, including Cdc42 and Rho, belong to the Ras superfamily of proteins that cycle between an inactive GDP-bound form and an active GTP-bound form. In this study, we show that Cdc42 and Rho play important but distinct roles in signal transduction and cytoskeleton reorganization in BAECs in response to shear stress. Upon exposure to shear stress, Cdc42 and Rho translocate from cytosol to membrane (Figure 1). Presumably, the activation of these two small GTPases is concurrent with their translocation. We have shown previously that the Ras-JNK pathway mediates the transcriptional activation driven by AP-1/TRE (16). The data presented in Figures 2 and 3 indicate that both Cdc 42 and Rho are involved but that only Cdc 42 is sufficient in the shear stress activation of JNK that leads to the
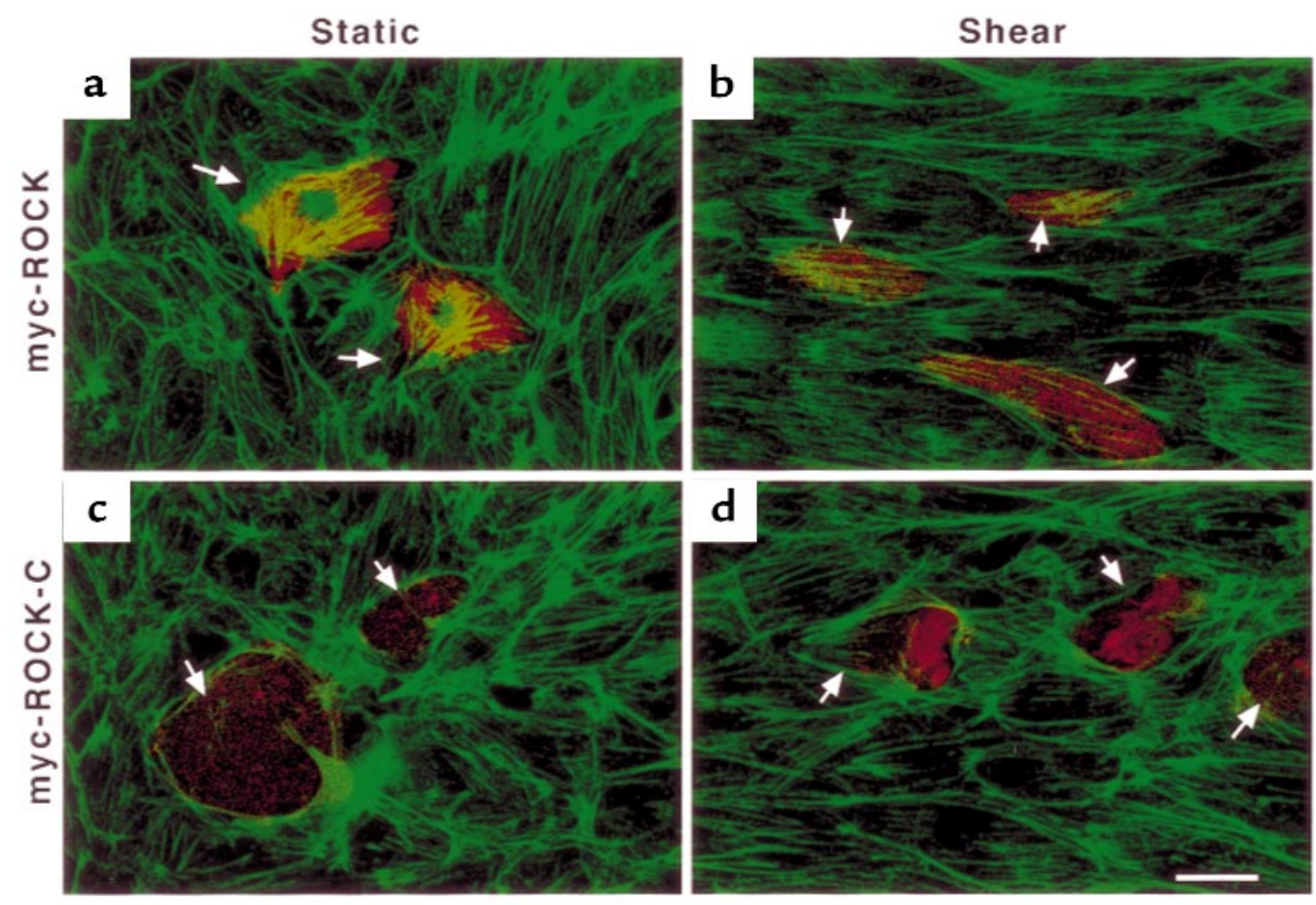

\section{Figure 6}

P160ROCK is a downstream effector of Rho in the shear stress regulation of EC alignment and stress fiber formation. The experimental conditions were the same as those in Figure 5, except that BAECs were transfected with either myc-ROCK (a and b) or myc-ROCK-C (c and $\mathbf{d})$ ( $2 \mu \mathrm{Hg} / \mathrm{slide})$. The static ( $\mathbf{a}$ and $\mathbf{c}$ ) or sheared ( $\mathbf{b}$ and $\mathbf{d}$ ) cells were fixed, permeabilized, double stained for actin and myc-tagged proteins, and observed by confocal microscopy. The actin-based cytoskeletal structure, which was recognized by FITC-conjugated phalloidin, is shown in green; the transfected cells, marked by anti-myc mAb recognized by rhodamine-conjugated goat anti-mouse IgG, are shown in red (arrows). Scale bar: 20 mm. 


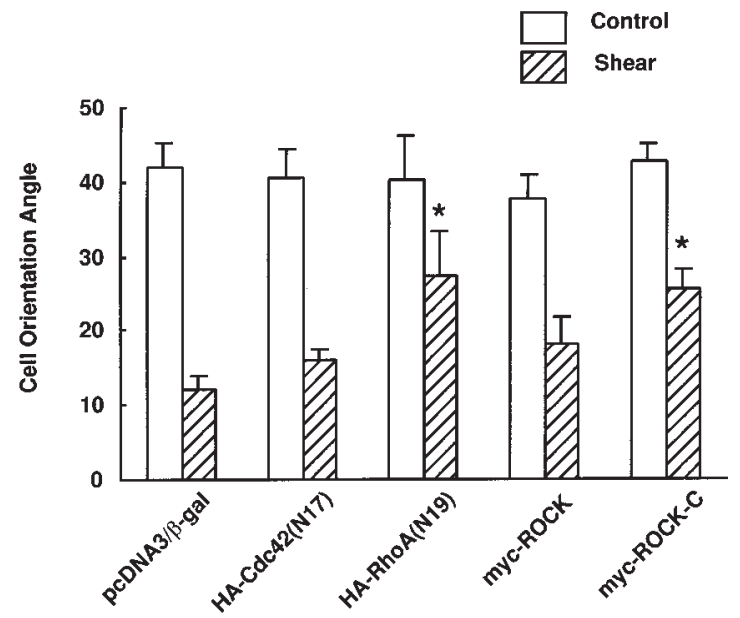

b

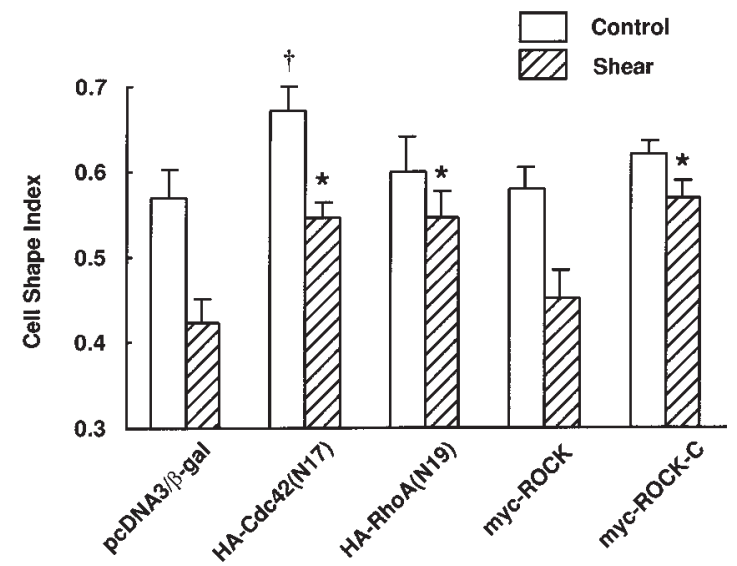

Figure 7

Summary of results on the cell orientation angles and cell shape indexes from specimens exemplified in Figures 5 and 6 . Two hundred transfected cells, identified by the $\beta$-gal-, HA-, or myc-positive staining and selected from at least three independent experiments, were subjected to analysis of the cell orientation angle (the angle between the cell principal axis and the flow direction) and cell shape index $(4 \pi \times$ cell area $) /($ cell perimeter squared). Bars represent mean \pm SEM. Significant differences $(P<$ $0.05)$ are indicated by the dagger for static conditions and by asterisks for sheared cells compared with pcDNA3-transfected cells.

increase in AP-1/TRE activity. Although both Cdc42 and Ras are sufficient for JNK activation, Ras(N17) was unable to inhibit the activation of JNK by Cdc42(V12), and neither can Cdc42(N17) inhibit the activation of JNK by Ras(V12) (Figure 4), indicating that Ras and Cdc42 in ECs activate JNK through parallel pathways. In contrast, Rho is involved but not sufficient for the shear stress activation of JNK, indicating that Rho regulates collectively with other molecules to activate JNK. This Rho-regulated pathway is independent of Cdc42 and Ras, as HA-RhoA(N19) did not inhibit mycCdc42(V12)-induced AP-1/TRE activity (Figure 2b) or the active mutant of RhoA-enhanced myc-Cdc42(V12) or Ras(V12)-induced TRE promoter activity (data not shown). On the other hand, Rho, but not Cdc42 and Ras, regulates the formation of stress fibers and the mor- phological remodeling (Figure 5) (50). Furthermore, p160ROCK functions as a Rho effector to regulate stress fiber formation and cell alignment (Figure 6) but not AP$1 /$ TRE activity (data not shown). These sequential events activated by shear stress are summarized in Figure 8.

The mechanism by which shear stress increases the translocation of RhoA and Cdc 42 from cytosol to membrane in ECs is not clear. It has been proposed that Rho GTPases bind to guanine nucleotide dissociation inhibitors (GDIs) in the cytosol. Upon stimulation, Rho GTPases dissociate from GDIs, translocate to the cell membrane, and become activated (reviewed in ref. 25). Previous studies have shown that incubation of neutrophil or Swiss 3T3 cell lysates with GTP $\gamma$ S increases the translocation of Cdc42 and Rho from cytosol to membrane $(44,45,51)$. Thus, the translocation of these two small GTPases to membrane by shear stress suggests that they are activated by shear stress. However, shear stress did not stimulate the redistribution of RhoA and Cdc42 into cytoskeleton. The lack of the cytoskeletal translocation of Rho GTPases has also been found in other cell types with chemical stimulation, e.g., in smooth muscle cells in response to phenylephrine (45).

The shear stress receptors or sensors in ECs that activate $\mathrm{Cdc} 42$ and Rho, leading to the subsequent signaling, have not been clearly identified. Growth factor receptors (i.e., receptor tyrosine kinases), G protein-coupled receptors, and integrins appear to be candidates, as they can mediate Cdc42 and Rho activation (26, 29, 37, 52-54). These shear stress-sensitive receptors may independently or coordinately regulate the activity of Rho GTPases. As receptors to extracellular matrix during cell adhesion, integrins may also serve as mechanosensors to shear stress. We have shown that shear stress rapidly increases integrin clustering (55). Many of the Cdc42and Rho-related signaling events, such as the activation of FAK, and c-Src, the assembly of focal adhesions and stress fibers, and the tyrosine phosphorylation of paxillin, are also induced in ECs by shear stress $(9,10)$. In agreement with this, integrin aggregation by using beads coated with ligands or anti-integrin antibodies triggered recruitment of signal transduction molecules, including RhoA, Rac, and Ras (52). It has been shown that integrinmediated focal adhesions are assembled only in the presence of both the appropriate extracellular matrix and functionally activated Rho or Rac (53). A recent study by Clark et al. (54) also showed that Rho GTPases play important roles in integrin-mediated cell adhesion, spreading, and signaling. The possible signaling events linking integrins to $\mathrm{Cdc} 42$ and Rho include guanine exchange factors (GEFs), GDIs, and GTPase-activating proteins (GAPs). For example, Graf (GTPase regulator associated with FAK), a new member of the GAP family, was recently cloned and shown to preferentially stimulate the GTPase activities of RhoA and Cdc42 (56).

Our finding that Rho-p160ROCK is involved in the shear stress regulation of cell alignment and stress fiber formation is in concert with previous studies on the involvement of $\mathrm{Ca}^{2+}$. Treatment with quin2-AM to chelate intracellular calcium abolishes cell shape change and stress fiber formation of BAECs in response to shear stress, indicating the involvement of calcium mobiliza- 
tion in these morphological and cytoskeletal modulations (23). Rho has been shown to increase calcium sensitization through p160ROCK in smooth muscle contraction (36). The GTP-bound, active form of RhoA inhibits myosin phosphatase activity by interacting with its myosin-binding subunit, which regulates the extent of MLC phosphorylation. In addition, p160ROCK or Rhokinase can enhance the phosphorylation of MLC by either inactivating myosin phosphatase or by directly phosphorylating MLC at the same site as MLCK does (34-36). Enhanced MLC phosphorylation increases actinomyosin contractility, stress fiber formation, and the recruitment of integrins into focal adhesion structures (37). There is ample evidence suggesting that MLCK phosphorylation of MLC is a critical signaling event associated with intracellular $\mathrm{Ca}^{2+}$ in actin-based cytoskeletal remodeling. It has recently been shown that ML-9, an inhibitor of MLCK, abolishes MLC phosphorylation and $\mathrm{Ca}^{2+}$ influx in porcine aortic ECs in response to shear stress (57). Thus, shear stress is likely to activate the Rhop160ROCK pathway, which in turn modulates the MLCK-MLC pathway or the intracellular $\mathrm{Ca}^{2+}$ to regulate the cell alignment and stress fiber formation.

Shear stress has been implicated in pathophysiological processes in the vascular wall such as atherosclerosis, reperfusion, and EC wound healing (1-8). Because both Cdc42 and Rho are sensitive to the applied shear stress, it is likely that these two small GTPases are involved in the EC signaling and gene expression in the lesion-prone areas of the arterial tree. The shear stress in these regions is constantly changing because of the pulsatile and disturbed blood flow pattern, which may be partially mimicked by a sudden change of shear stress in vitro. The activation of Cdc42 and Rho, and their engagement in JNK activation in response to the applied shear stress, may also play important roles in reperfusion injury. It has been shown that reperfusion, but not ischemia, activates JNK in the ischemic-reperfused heart $(58,59)$. The sustained activation of Rho is consistent with its important role in EC remodeling under shear stress. Because endothelial integrity is critical in maintaining the homeostasis of the blood vessel wall, damage to the endothelium often results in endothelial remodeling. After balloon angioplasty, ECs migrate as a monolayer at the wounding edge, with very few migrating as single cells, and the migration is followed by proliferation (60). Both in vivo and in vitro studies have demonstrated that shear stress enhances EC remodeling after injury, possibly by increasing cell migration $(5,6)$. Recently, it has been shown that C3 exoenzyme inhibits EC wound closure under static culture conditions (61). These studies, together with our results, suggest that Rho GTPase is important in EC remodeling under flow.

In summary, our findings have implications in understanding the roles of shear stress in initiation of atherosclerosis, reperfusion, and EC wound healing. The activation of immediate early genes and cytoskeletal reorganization in response to shear stress is crucial in vascular homeostasis in physiological and pathophysiological conditions. Our results suggest that Rho GTPases are important molecules in mediating these cellular events.
Shear Stress

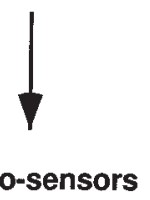

e.g. RTK, G proteins, Integrins ?

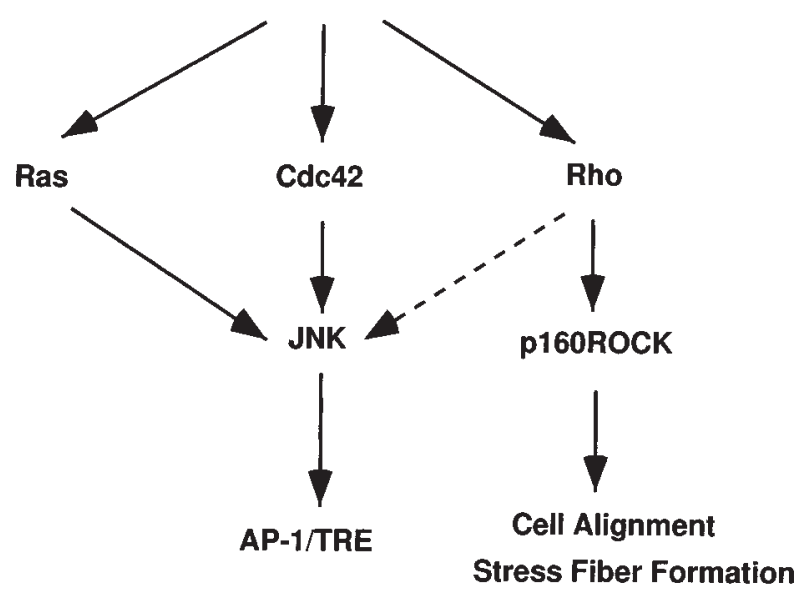

Figure 8

A proposed model to show the possible roles of Ras, Rho, and Cdc42 GTPases in shear stress-induced signal transduction and actin-based cytoskeleton reorganization in ECs.

\section{Acknowledgments}

We thank Michael Karin (University of California-San Diego) and Martin Schwartz (The Scripps Research Institute) for providing myc-Cdc42(V12), myc-RhoA(V14), HA-Cdc42(N17), and HA-RhoA(N19); and Shuh Narumiya for providing mycROCK, myc-ROCK-C, and recombinant C3. This work was supported in part by research grants HL-19454 and HL-43026 (to S. Chien) and HL-56707 and HL-60789 (to J. Y.-J. Shyy) from the National Heart, Lung, and Blood Institute of the National Institutes of Health, and by a Scientist Development Grant from the American Heart Association (to S. Li). We greatly appreciate the valuable discussions with Shunichi Usami, Martin Schwartz, Jun-lin Guan, and Y.-S. Li, and the excellent technical assistance of Suli Yuan.

1. Caro, C.G., Fitz-gerald, J.M., and Schroter, R.C. 1971. Atheroma and arterial wall shear: observation, correlation and proposal of shear dependent mass transfer mechanisms for atherogenesis. Proc. R. Soc. Lond. B Biol. Sci. 177:109-159.

2. Ku, D.N., Giddens, D.P., Zarins, C.K., and Glagov, S. 1985. Pulsatile flow and atherosclerosis in the human carotid bifurcation. Positive correlation between plaque location and low oscillating shear stress. Arteriosclerosis. 5:293-302.

3. Glagov, S., Zarins, C., Giddens, D.P., and Ku, D.N. 1988. Hemodynamics and atherosclerosis. Insights and perspectives gained from studies of human arteries. Arch. Pathol. Lab. Med. 112:1018-1031.

4. Giddens, D.P., Zarins, C.K., and Glagov, S. 1993. The role of fluid mechanics in the localization and detection of atherosclerosis. J. Biomech. Eng. 115:588-594.

5. Wu, M.H., et al. 1995. Effect of differential shear stress on platelet aggregation, surface thrombosis, and endothelialization of bilateral carotidfemoral grafts in the dog. J. Vasc. Surg. 22:382-390.

6. Sprague, E.A., Luo, J., and Palmaz, J.C. 1997. Human aortic endothelial cell migration onto stent surfaces under static and flow conditions. $J$. Vasc. Interv. Radiol. 8:83-92. 
7. Soler, H.M., Watkins, M.T., Albadawi, H., Kadowaki, H., and Patton, G.M. 1997. Effects of oxygen tension and shear stress on human endothelial cell prostacyclin production. J. Surg. Res. 67:46-53.

8. Al-Mehdi, A.B., Zhao, G., and Fisher, A.B. 1998. ATP-independent membrane depolarization with ischemia in the oxygen-ventilated isolated rat lung. Am. J. Respir. Cell Mol. Biol. 18:653-661.

9. Davies, P.F. 1995. Flow-mediated endothelial mechanotransduction. Physiol. Rev. 75:519-560.

10. Chien, S., Li, S., and Shyy, Y.J. 1998. Effects of mechanical forces on signal transduction and gene expression in endothelial cells. Hypertension. 31:162-169.

11. Resnick, N., et al. 1993. Platelet-derived growth factor B chain promoter contains a cis-acting fluid shear-stress-responsive element. Proc. Natl. Acad. Sci. USA. 90:4591-4595.

12. Nagel, T., Resnick, N., Atkinson, W.J., Dewey, C.J., and Gimbrone, M.J. 1994. Shear stress selectively upregulates intercellular adhesion molecule1 expression in cultured human vascular endothelial cells. J. Clin. Invest. 94:885-891

13. Shyy, Y.-J., Hsieh, H.J., Usami, S., and Chien, S. 1994. Fluid shear stress induces a biphasic response of human monocyte chemotactic protein 1 gene expression in vascular endothelium. Proc. Natl. Acad. Sci. USA. 91:4678-4682.

14. Hsieh, H.J., Li, N.Q., and Frangos, J.A. 1993. Pulsatile and steady flow induces c-fos expression in human endothelial cells. J. Cell. Physiol. 154:143-151.

15. Tseng, H., Peterson, T.E., and Berk, B.C. 1995. Fluid shear stress stimulates mitogen-activated protein kinase in endothelial cells. Circ. Res. 77:869-878.

16. Li, Y.S., et al. 1996. The Ras-JNK pathway is involved in shear-induced gene expression. Mol. Cell. Biol. 16:5947-5954.

17. Shyy, J.Y., et al. 1995. The cis-acting phorbol ester "12-O-tetradecanoylphorbol 13-acetate"-responsive element is involved in shear stress-induced monocyte chemotactic protein 1 gene expression. Proc. Natl. Acad. Sci. USA. 92:8069-8073.

18. Levesque, M.J., and Nerem, R.M. 1985. The elongation and orientation of cultured endothelial cells in response to shear stress. J. Biomech. Eng. 107:341-347

19. Davies, P.F., Robotewskyj, A., and Griem, M.L. 1994. Quantitative studies of endothelial cell adhesion. Directional remodeling of focal adhesion sites in response to flow forces. J. Clin. Invest. 93:2031-2038

20. Girard, P.R., and Nerem, R.M. 1993. Endothelial cell signaling and cytoskeletal changes in response to shear stress. Front. Med. Biol. Eng. 5:31-36.

21. Girard, P.R., and Nerem, R.M. 1995. Shear stress modulates endothelial cell morphology and F-actin organization through the regulation of focal adhesion-associated proteins. J. Cell. Physiol. 163:179-193.

22. Kim, D.W., Gotlieb, A.I., and Langille, B.L. 1989. In vivo modulation of endothelial F-actin microfilaments by experimental alterations in shear stress. Arteriosclerosis. 9:439-445.

23. Malek, A.M., and Izumo, S. 1996. Mechanism of endothelial cell shape change and cytoskeletal remodeling in response to fluid shear stress. J. Cell Sci. 109:713-726.

24. Lim, L., Manser, E., Leung, T., and Hall, C. 1996. Regulation of phosphorylation pathways by p 21 GTPases. The p 21 Ras-related Rho subfamily and its role in phosphorylation signalling pathways. Eur. J. Biochem. 242:171-185.

25. Aelst, L.V., and D'Souza-Schorey, C. 1997. Rho GTPases and signaling networks. Genes Dev. 11:2295-2322.

26. Nobes, C.D., and Hall, A. 1995. Rho, rac, and cdc42 GTPases regulate the assembly of multimolecular filopodia. Cell. 81:53-62.

27. Kozma, R., Ahmed, S., Best, A., and Lim, L. 1995. The Ras-related protein $\mathrm{Cdc} 42 \mathrm{Hs}$ and bradykinin promote formation of peripheral actin microspikes and filopodia in Swiss 3T3 fibroblasts. Mol. Cell. Biol. 15:1942-1952.

28. Ridley, A.J., Paterson, H.F., Johnston, C.L., Diekmann, D., and Hall, A. 1992. The small GTP-binding protein rac regulates growth factor-induced membrane ruffling. Cell. 70:401-410.

29. Ridley, A.J., and Hall, A. 1992. The small GTP-binding protein rho regulates the assembly of focal adhesions and actin stress fibers in response to growth factors. Cell. 70:389-399.

30. Ridley, A.J., and Hall, A. 1994. Signal transduction pathways regulating Rho-mediated stress fibre formation: requirement for a tyrosine kinase. EMBO J. 13:2600-2610.

31. Khosravi, F.R., et al. 1994. Dbl and Vav mediate transformation via mitogen-activated protein kinase pathways that are distinct from those activated by oncogenic Ras. Mol. Cell. Biol. 14:6848-6857.

32. Flinn, H.M., and Ridley, A.J. 1996. Rho stimulates tyrosine phosphorylation of focal adhesion kinase, p130 and paxillin. J. Cell Sci. 109:1133-1141.

33. Ishizaki, T., et al. 1997. p160ROCK, a Rho-associated coiled-coil forming protein kinase, works downstream of Rho and induces focal adhesions. FEBS Lett. 404:118-124.

34. Kimura, K., et al. 1996. Regulation of myosin phosphatase by Rho and Rho-associated kinase (Rho-kinase). Science. 273:245-248.
35. Amano, M., et al. 1996. Phosphorylation and activation of myosin by Rhoassociated kinase (Rho-kinase). J. Biol. Chem. 271:20246-20249.

36. Uehata, M., et al. 1997. Calcium sensitization of smooth muscle mediated by a Rho-associated protein kinase in hypertension Nature. 389:990-994.

37. Chrzanowska, W.M., and Burridge, K. 1996. Rho-stimulated contractility drives the formation of stress fibers and focal adhesions. J. Cell Biol. 133:1403-1415.

38. Minden, A., Lin, A., Claret, F.X., Abo, A., and Karin, M. 1995. Selective activation of the JNK signaling cascade and c-Jun transcriptional activity by the small GTPases Rac and Cdc42Hs. Cell. 81:1147-1157.

39. Coso, O.A., et al. 1995. The small GTP-binding proteins Rac1 and Cdc42 regulate the activity of the JNK/SAPK signaling pathway. Cell. 81:1137-1146.

40. Renshaw, M.W., Toksoz, D., and Schwartz, M.A. 1996. Involvement of the small GTPase rho in integrin-mediated activation of mitogen-activated protein kinase. J. Biol. Chem. 271:21691-21694.

41. Frangos, J.A., Eskin, S.G., McIntire, L.V., and Ives, C.L. 1985. Flow effects on prostacyclin production by cultured human endothelial cells. Science. 227:1477-1479

42. Ren, X.D., Kiosses, W.B., and Schwartz, M.A. 1999. Regulation of the small GTP-binding protein Rho by cell adhesion and the cytoskeleton. EMBOJ. 18:578-585

43. Zhang, S., et al. 1995. Rho family GTPases regulate p38 mitogen-activated protein kinase through the downstream mediator Pak1. J. Biol. Chem. 270:23934-23936.

44. Fleming, I.N., Elliott, C.M., and Exton, J.H. 1996. Differential translocation of rho family GTPases by lysophosphatidic acid, endothelin-1, and platelet-derived growth factor. J. Biol. Chem. 271:33067-33073.

45. Gong, M.C., Fujihara, H., Somlyo, A.V., and Somlyo, A.P. 1997. Translocation of rhoA associated with $\mathrm{Ca}^{2+}$ sensitization of smooth muscle. J. Biol. Chem. 272:10704-10709.

46. Karnam, P., Standaert, M.L., Galloway, L., and Farese, R.V. 1997. Activation and translocation of Rho (and ADP ribosylation factor) by insulin in rat adipocytes. Apparent involvement of phosphatidylinositol 3-kinase. J. Biol. Chem. 272:6136-6140

47. Kumagai, N., Morii, N., Fujisawa, K., Nemoto, Y., and Narumiya, S. 1993. ADP-ribosylation of rho $\mathrm{p} 21$ inhibits lysophosphatidic acid-induced protein tyrosine phosphorylation and phosphatidylinositol 3-kinase activation in cultured Swiss 3T3 cells. J. Biol. Chem. 268:24535-24538.

48. Yano, Y., Saito, Y., Naruyama, S., and Sumpio, B.E. 1996. Involvement of rho p21 in cyclic strain-induced tyrosine phosphorylation of focal adhesion kinase (pp125FAK), morphological changes and migration of endothelial cells. Biochem. Biophys. Res. Commun. 224:508-515.

49. Jo, H., et al. 1997. Differential effect of shear stress on extracellular signalregulated kinase and N-terminal Jun kinase in endothelial cells. Gi2- and G $\beta / \gamma$-dependent signaling pathways. J. Biol. Chem. 272:1395-1401.

50. Li, S., et al. 1997. Ras is not necessary in shear stress-induced cell alignment in endothelial cells. Ann. Biomed. Eng. 25:S-54. (Abstr.)

51. Bokoch, G.M., Bohl, B.P., and Chuang, T.H. 1994. Guanine nucleotide exchange regulates membrane translocation of Rac/Rho GTP-binding proteins. J. Biol. Chem. 269:31674-31679.

52. Miyamoto, S., et al. 1995. Integrin function: molecular hierarchies of cytoskeletal and signaling molecules. J. Cell Biol. 131:791-805.

53. Hotchin, N.A., and Hall, A. 1995. The assembly of integrin adhesion complexes requires both extracellular matrix and intracellular rho/rac GTPases. J. Cell Biol. 131:1857-1865.

54. Clark, E.A., King, W., Brugge, J.S., Symons, M., and Hynes, R.O. 1998. Integrin-mediated signals regulated by members of the Rho family of GTPases. J. Cell Biol. 142:573-586.

55. Li, S., et al. 1997. Fluid shear stress activation of focal adhesion kinase. Linking to mitogen-activated protein kinases. J. Biol. Chem. 272:30455-30462.

56. Hildebrand, J.D., Taylor, J.M., and Parsons, J.T. 1996. An SH3 domain-containing GTPase-activating protein for Rho and Cdc42 associates with focal adhesion kinase. Mol. Cell. Biol. 16:3169-3178.

57. Watanabe, H., et al. 1998. An essential role of myosin light-chain kinase in the regulation of agonist- and fluid flow-stimulated $\mathrm{Ca}^{2+}$ influx in endothelial cells. FASEB J. 12:341-348.

58. Bogoyevitch, M.A., et al. 1996. Stimulation of the stress-activated mitogen-activated protein kinase subfamilies in perfused heart. p38/RK mitogen-activated protein kinases and c-Jun $\mathrm{N}$-terminal kinases are activated by ischemia/reperfusion. Circ. Res. 79:162-173.

59. Mizukami, Y., K.Yoshioka, S. Morimoto, and K.i. Yoshida. 1997. A novel mechanism of JNK1 activation. Nuclear translocation and activation of JNK1 during ischemia and reperfusion. J. Biol. Chem. 272:16657-16662.

60. Schwartz, S.M., Haudenschild, C.C., and Eddy, E.M. 1978. Endothelial regeneration. I. Quantitative analysis of initial stages of endothelial regeneration in rat aortic intima. Lab. Invest. 38:568-580.

61. Aepfelbacher, M., Essler, M., Huber, E., Sugai, M., and Weber, P.C. 1997. Bacterial toxins block endothelial wound repair. Evidence that Rho GTPases control cytoskeletal rearrangements in migrating endothelial cells. Arterioscler. Thromb. Vasc. Biol. 17:1623-1629. 